\title{
Thermo-mechanical treatment regulation of microstructure and comprehensive performance in $\mathrm{Al}-\mathrm{Zn}-\mathrm{Mg}-\mathrm{Cu}$ alloy
}

\author{
Zhiguo Chen ${ }^{1,2,}$, Chenghua Lu$^{2}$, Jing Peng ${ }^{2}$, and Zhengui Yuan ${ }^{2}$ \\ ${ }^{1}$ Department of Materials Engineering, Hunan University of Humanities, Science and Technology, Loudi 417000, P.R. China \\ ${ }^{2}$ School of Materials Science and Engineering, Central South University, Changsha 410083, P. R. China
}

\begin{abstract}
The comprehensive performance of $\mathrm{Al}-\mathrm{Zn}-\mathrm{Mg}-\mathrm{Cu}$ alloy can be significantly improved by a proposed novel thermo-mechanical treatment (NTMT). The influence of the NTMT on the properties and microstructure was investigated by tensile test, corrosion resistance test, X-ray diffraction (XRD), and transmission electron microscopy (TEM). Results show that $\mathrm{Al}-\mathrm{Zn}-\mathrm{Mg}-\mathrm{Cu}$ alloy treated by the NTMT can obtain an excellent combination of strength and ductility. The highest yield strength and ultimate tensile strength reached $643 \mathrm{MPa}$ and $664 \mathrm{MPa}$ respectively, and the elongation was 9.7\%. Meanwhile, electrochemical corrosion resistance and intergranular corrosion resistance in the aluminum alloy can be improved after the NTMT. The mechanism of the excellent combination of strength and ductility is thought to be the synergistic effect of dislocations substructures, texture configuration, and nanoprecipitates. The improvement of intergranular corrosion resistance of the aluminum alloy is caused by changes in the micro-morphology of grain boundary precipitates after the NTMT, which can block anodic dissolution channels along grain boundaries to reduce the rate of anodic dissolution and avoid hydrogen embrittlement.
\end{abstract}

\section{Introduction}

$\mathrm{Al}-\mathrm{Zn}-\mathrm{Mg}-\mathrm{Cu}$ alloys can be used in aerospace and construction materials due to their high strength, low density, and good thermal processing performance, and they have a great application prospect [1-4]. However, they are sensitive to intergranular corrosion (IGC), stress corrosion cracking (SCC), and exfoliation corrosion (EXCO) [5, 6], which limit their practical application. In order to meet the application requirements, it is essential to properly select and design processes to improve the strength and corrosion resistance of aluminum alloys. In the early 1960s, Alcoa developed T73 and T76 processes, which improved the stress corrosion resistance of 7075 and 7079 aluminum alloys in the peak ageing process, but at the same time, part of the strength of the alloy was sacrificed [7]. In 1974, the Israeli Cina [8] put forward a multi-step ageing process named the regression and re-ageing (RRA), in which the corrosion resistance of aluminum alloys was improved without sacrificing strength simultaneously. However, it is not convenient for large-scale applications since the alloy plate is required to be kept at a high temperature for a short retrogression time.

Numerous studies have shown that the thermo-mechanical treatment (TMT) has the advantages of high productivity, low cost, and practicality of continuous production [9], and it is a practical method to improve the mechanical properties of aluminum alloys. Huo et al. [10] proposed a TMT combining with warm rolling and continuous rolling treatment, which successfully refined grains of 7075 aluminum alloy to 10 $\mu \mathrm{m}$, improving the strength and ductility of aluminum alloys. Li et al. [11] used 83\% cold deformation and then ageing $\left(100^{\circ} \mathrm{C}, 72 \mathrm{~h}\right)$, and the yield strength of 2024 aluminum alloy reached $711 \mathrm{MPa}$. Zuo et al. [12] proposed a TMT including pre-deformation, intermediate short-term annealing, and final hot rolling, obtaining

\footnotetext{
$\overline{{ }^{*} \text { Corresponding author: hngary@163.com }}$
} 
superior elongation while maintaining high strength in AA7055 alloy.

In our previous work, a good combination of strength and ductility could be achieved in 2E12 aluminum alloy by a novel thermo-mechanical treatment (NTMT) [13]. Moreover, we achieved an excellent combination of strength and ductility in Al-Mg-Si alloy by the NTMT based on cluster strengthening [14]. Given the results above, we proposed the NTMT based on continuous Solid solution-Hot rolling to solve the preparation of high strength and good ductility $\mathrm{Al}-\mathrm{Zn}-\mathrm{Mg}-\mathrm{Cu}$ alloy with good intergranular corrosion resistance, which might provide a new idea for the preparation of high comprehensive properties aluminum alloys to meet the demand for aerospace and other high technology. The effects of the NTMT on the comprehensive properties in $\mathrm{Al}-\mathrm{Zn}-\mathrm{Mg}-\mathrm{Cu}$ alloy are discussed. More importantly, the involved mechanism is discussed in depth, which can lay the foundation for the research in other series of aluminum alloys.

\section{Materials and methods}

The material used in this research was an $\mathrm{Al}-\mathrm{Zn}-\mathrm{Mg}-\mathrm{Cu}$ alloy plate with an original thickness of $12 \mathrm{~mm}$. The chemical composition of the studied alloy is given in Table 1.

Table 1. Chemical composition of $\mathrm{Al}-\mathrm{Zn}-\mathrm{Mg}-\mathrm{Cu}$ alloy (w.t. \%).

\begin{tabular}{cccccccc}
$\mathrm{Zn}$ & $\mathrm{Mg}$ & $\mathrm{Cu}$ & $\mathrm{Fe}$ & $\mathrm{Si}$ & $\mathrm{Zr}$ & $\mathrm{Mn}$ & $\mathrm{Al}$ \\
\hline 6.20 & 2.35 & 2.23 & 0.15 & 0.12 & 0.10 & 0.10 & $\mathrm{Bal}$. \\
\hline
\end{tabular}

The samples were processed by T6 and RRA, respectively. The $\mathrm{T} 6$ treatment was solution treatment $\left(475^{\circ} \mathrm{C} / 1 \mathrm{~h}\right)$ +water quenching+ageing $\left(120^{\circ} \mathrm{C} / 24 \mathrm{~h}\right)$. The RRA treatment was solution treatment $\left(475^{\circ} \mathrm{C} / 1 \mathrm{~h}\right)$ +ageing $\left(120^{\circ} \mathrm{C} / 24 \mathrm{~h}\right)$ +regression heat treatment $\left(195^{\circ} \mathrm{C} / 10 \mathrm{~min}\right)$ +ageing $\left(120^{\circ} \mathrm{C} / 24 \mathrm{~h}\right)$. The schematic diagram of NTMT is illustrated in Fig. 1. The steps included continuous Solid solution-Hot rolling (SSHR), deformation treatment, and ageing treatment. The continuous SSHR was the alloys first heated at $475^{\circ} \mathrm{C}$ for $1 \mathrm{~h}$, and immediately followed by hot rolling with a deformation rate of $30 \%$. The reduction value of cold rolling treatment was $60 \%$. Finally, different ageing treatments were carried out.

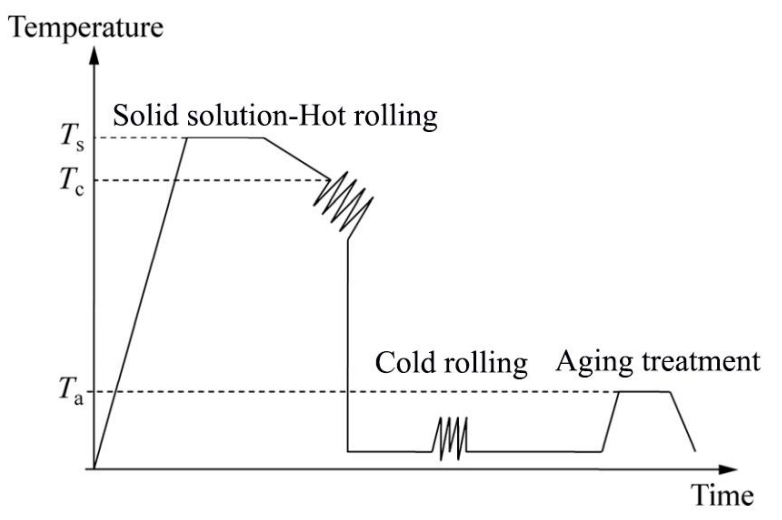

Fig. 1. Schematic diagram of the NTMT in aluminum alloys.

The tensile specimens (the gauge length/width/thickness of $30 \mathrm{~mm} / 8 \mathrm{~mm} / 2.4 \mathrm{~mm}$ ) were performed on the MTS- 858 universal testing machine at room temperature with a constant strain rate of 2.0 $\mathrm{mm} / \mathrm{min}$. Three parallel samples were tested for each data point to obtain consistent yield strength, tensile strength, and elongation. The optical microscopy (OM) of the specimens was observed using a Leica DMILM optical microscope model. The susceptibility to intergranular corrosion (IGC) was assessed according to the GB/T7998-2005 standard. The specimens (testing area/ solution volume $<20 \mathrm{~mm}^{2} / \mathrm{mL}$ ) were immersed in the reagent $\left(57 \mathrm{~g} / \mathrm{L} \mathrm{NaCl}+10 \mathrm{~mL} / \mathrm{L} \mathrm{H}_{2} \mathrm{O}_{2}\right.$ solution) at a temperature of $35^{\circ} \mathrm{C}$ and for a time of $6 \mathrm{~h}$. The TEM specimens were mechanically thinned to $80-100 \mu \mathrm{m}$, then the mixture of nitric acid and methanol with a volume ratio of 1:3 was used for twin-jet electropolishing below $-25^{\circ} \mathrm{C}$. TEM observations were performed on TecnaiG 20 transmission electron microscopy with an operating voltage of $200 \mathrm{kV}$. The electrical conductivity is obtained by the relationship between the resistivity and the electrical conductivity. The resistance of the samples was measured by a double-arm bridge detector, and then the resistivity $\rho$ can be obtained by the Equation (1):

$$
R=\rho l / S
$$

where $\rho$ is the resistivity, $l$ is the sample length, and $S$ is the sample boundary area. XRD measurements were made on Rigaku D/max 2500 X-ray diffractometer to observe the texture evolution and measure the dislocation density of samples. 


\section{Results}

\subsection{Tensile properties}

As shown in Table 2, the yield strength (YS) and ultimate tensile strength (UTS) of the $\mathrm{Al}-\mathrm{Zn}-\mathrm{Mg}-\mathrm{Cu}$ alloy in the T6 and RRA tempers are very close. However, the elongation $(\delta)$ of the aluminum alloy in the T6 is higher than that of RRA. Compared with T6 and RRA, the UTS and YS of NTMT processed samples are significantly improved. The elongation of the aluminum alloy after the NTMT is lower than that of T6, but it is close to the RRA. An outstanding combination of strength and ductility is achieved in the condition of 30\% continuous Solid solution-Hot rolling (SSHR) $+60 \%$ cold rolling (CR) +ageing treatment $\left(120^{\circ} \mathrm{C} / 6 \mathrm{~h}\right)$, the highest YS and UTS reached $643 \mathrm{MPa}$ and $664 \mathrm{MPa}$ respectively, meanwhile, the elongation was $9.7 \%$. The elongation value of NTMT processed alloy increased first and then decreased. The elongation of H3C6A18 was $10.6 \%$, which is the best ductility in NTMT processed samples, but the strength of sample $\mathrm{H} 3 \mathrm{C} 6 \mathrm{~A} 18$ is lower than that of H3C6A6.

\subsection{Electrical conductivity and corrosion property test}

Table 3 shows the electrical performance parameters of $\mathrm{Al}-\mathrm{Zn}-\mathrm{Mg}-\mathrm{Cu}$ alloys after different processes. It can be seen that the conductivity of NTMT processed samples is between T6 (30.66\%IACS) and RRA (35.28\%IACS), and its conductivity gradually increases with the extension of ageing time. The H3C6A24 sample has the highest conductivity in NTMT processed samples, which is close to that of RRA. The H3C6A6 sample has the lowest conductivity in NTMT processed samples, but significantly higher than that of $\mathrm{T} 6$.

As shown in Table 3, after $30 \% \mathrm{SSHR}+60 \% \mathrm{CR}$, the longer the ageing time, the smaller the electrochemical corrosion current density ( $\mathrm{i}_{\text {corr }}$ ), the slower the corrosion rate, and the better the corrosion resistance. The corrosion current density is lower than that of $\mathrm{T} 6$ when the ageing time reaches 12 hours, and it is even less than that of RRA when the ageing time reaches 18 hours.

During the intergranular corrosion test, many white corrosion products could be observed on the surface of T6, RRA and NTMT processed samples. Some samples had the phenomenon of surface warping after corrosion. Due to the different treatments, the intergranular corrosion morphology of each sample is also quite different. The corrosion morphology of the T6 and RRA processed samples shows an obvious corrosion ditch, as shown in Fig. 2(a, b). However, the intergranular corrosion cross-section of the sample exhibited a fibrous morphology due to the rolling deformation (Fig. 2(c-f)). The corrosion depths of samples in the T6 and RRA were $81.67 \mu \mathrm{m}$ and $52.50 \mu \mathrm{m}$, respectively, implying that the intergranular corrosion resistance of the T6 was inferior to that of the RRA. The corrosion depths of samples in the H3C6A6, H3C6A12, H3C6A18, and H3C6A24 were $62.84 \mu \mathrm{m}, 39.86 \mu \mathrm{m}, 29.05 \mu \mathrm{m}$, and $27.70 \mu \mathrm{m}$, respectively. It indicates that the intergranular corrosion depth of NTMT processed samples gradually decreases, which means that the intergranular corrosion resistance of the samples is improved with the extension of ageing time. It should be noted that the intergranular corrosion resistance in the NTMT processed samples is

Table 2. Tensile properties of $\mathrm{Al}-\mathrm{Zn}-\mathrm{Mg}-\mathrm{Cu}$ alloys in different states.

\begin{tabular}{ccccc}
\hline Sample & Treatment & UTS (MPa) & YS (MPa) & $\delta(\%)$ \\
\hline T6 & $475 \mathrm{C} / 1 \mathrm{~h}+12^{\circ} \mathrm{C} / 24 \mathrm{~h}$ & $601 \pm 3$ & $525 \pm 5$ & $15.0 \pm 0.7$ \\
RRA & $475^{\circ} \mathrm{C} / 1 \mathrm{~h}+120 \mathrm{C} / 24 \mathrm{~h}+195^{\circ} \mathrm{C} / 10 \mathrm{~min}$ & $608 \pm 4$ & $529 \pm 4$ & $11.6 \pm 0.5$ \\
& $+120{ }^{\circ} \mathrm{C} / 24 \mathrm{~h}$ & & \\
H3C6A6 & $30 \% \mathrm{SSHR}+60 \% \mathrm{CR}+120^{\circ} \mathrm{C} / 6 \mathrm{~h}$ & $664 \pm 5$ & $643 \pm 4$ & $9.7 \pm 0.5$ \\
H3C6A12 & $30 \% \mathrm{SSHR}+60 \% \mathrm{CR}+120^{\circ} \mathrm{C} / 12 \mathrm{~h}$ & $658 \pm 4$ & $636 \pm 3$ & $10.1 \pm 0.8$ \\
H3C6A18 & $30 \% \mathrm{SSHR}+60 \% \mathrm{CR}+120^{\circ} \mathrm{C} / 18 \mathrm{~h}$ & $651 \pm 5$ & $633 \pm 4$ & $10.6 \pm 0.7$ \\
$\mathrm{H} 3 \mathrm{C} 6 \mathrm{~A} 24$ & $30 \% \mathrm{SSHR}+60 \% \mathrm{CR}+120^{\circ} \mathrm{C} / 24 \mathrm{~h}$ & $642 \pm 4$ & $620 \pm 4$ & $9.4 \pm 0.7$ \\
\hline
\end{tabular}


greatly improved compared with that of T6. The intergranular corrosion depth of the samples after 12 hours ageing is lower than that of RRA.

Table 3. The electrical performance parameters of $\mathrm{Al}-\mathrm{Zn}-\mathrm{Mg}-\mathrm{Cu}$ alloys.

\begin{tabular}{cccc}
\hline Sample & $\begin{array}{c}\text { Conductivity } \\
(\% \mathrm{IACS})\end{array}$ & $\mathrm{E}_{\text {corr }}(\mathrm{V})$ & $\begin{array}{c}\mathrm{I}_{\text {corr }} \\
\left(\mathrm{A} \cdot \mathrm{mm}^{-2}\right)\end{array}$ \\
\hline T6 & 30.66 & -1.364 & $1.50 \times 10^{-6}$ \\
RRA & 35.28 & -1.289 & $1.05 \times 10^{-6}$ \\
H3C6A6 & 32.16 & -1.317 & $1.54 \times 10^{-6}$ \\
H3C6A12 & 33.10 & -1.347 & $1.07 \times 10^{-6}$ \\
H3C6A18 & 34.25 & -1.324 & $8.62 \times 10^{-7}$ \\
H3C6A24 & 34.63 & -1.319 & $7.36 \times 10^{-7}$ \\
\hline
\end{tabular}

\subsection{Metallographic observation}

Fig. 3 shows the optical micrographs of Al-Zn-Mg-Cu alloys in different states. It can be seen that most grains of T6 and RRA processed samples have recrystallized and grown up at the solid solution temperature, and their grain sizes are similar, both are equiaxed crystals. However, the grains in NTMT processed samples are elongated due to rolling deformation and formed fibrous structures, which also explains why the intergranular corrosion morphologies of the samples in Fig. 2 are fibrous. What's more, the fibrous grain structure formed in deformation hinders the corrosion crack growth.

\subsection{Dislocation density and texture analysis}

The dislocation density is calculated using the following Equation (2) [15]:

$$
\rho=2 \sqrt{3} \varepsilon /(d b)
$$

where $\rho$ represents the dislocation density, $\varepsilon$ represents the micro-strain, $d$ represents the crystallite size, and $b=0.286 \mathrm{~nm}$ is the Burgers vector of $\alpha-\mathrm{Al}$. The crystallite size and micro stress are obtained by the half-width of the diffraction peak according to the Williamson-Hall method [16], which can be expressed by the following Equation (3):

$$
(B \cos \theta / \lambda)^{n}=(1 / D)^{n}+(4 \varepsilon \sin \theta / \lambda)^{n}
$$

where $B$ is half-width of the diffraction peak, $\lambda$ is the wavelength of X-ray, $D$ is the crystallite size, $\varepsilon$ is the micro-strain, $\theta$ is the semi-diffraction angle, and $n$ is the deconvolution parameter. Fig. 4 illustrates the dislocation densities of alloys under the process of $30 \% \mathrm{SSHR}+60 \% \mathrm{CR}$. It can be concluded that the dislocation density decreases with the increase of ageing time, which indicates that the dislocations have a certain degree of recovery, causing some entangled dislocations to disappear and the dislocation density to decrease.
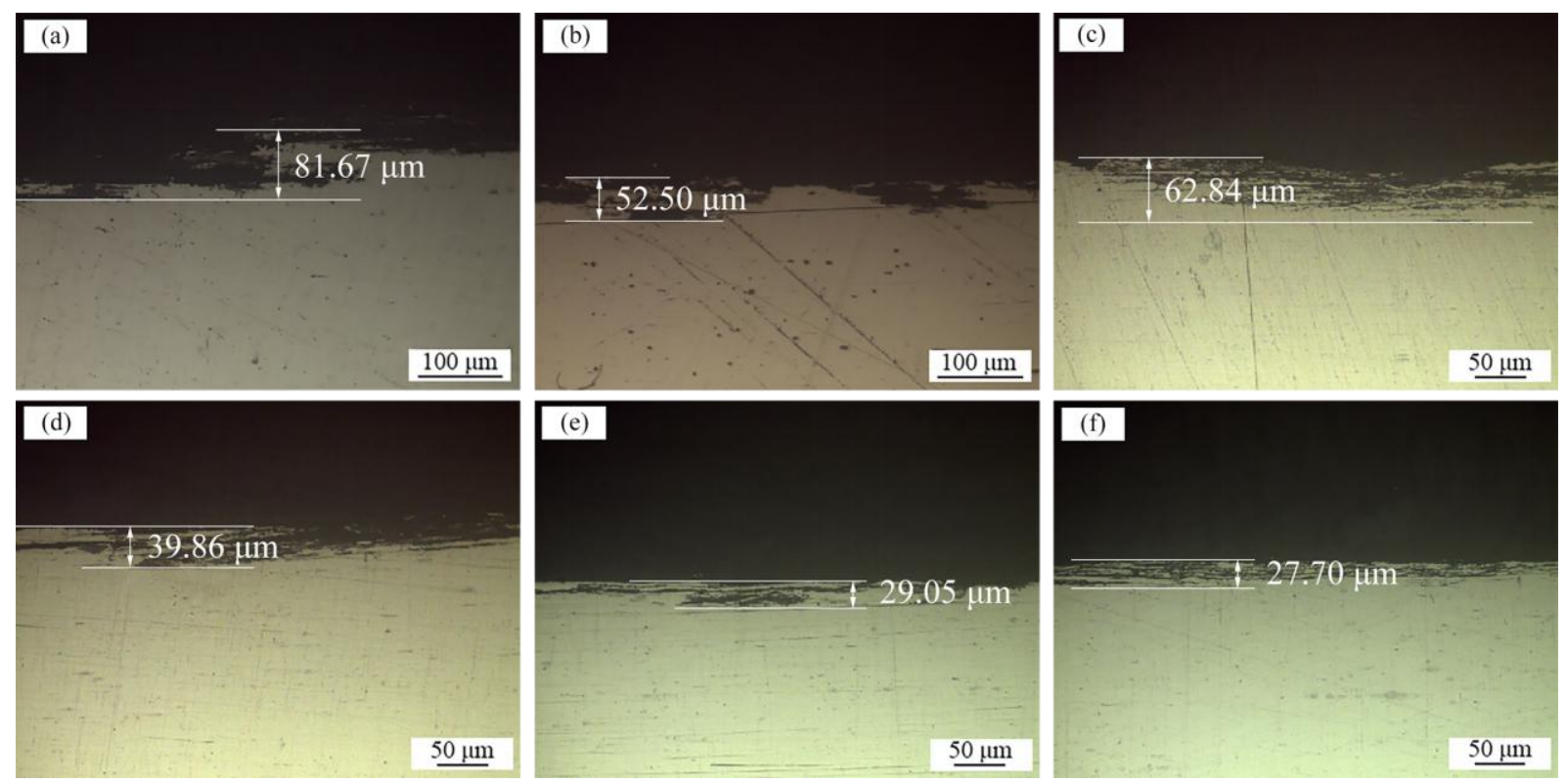

Fig. 2. Intergranular corrosion morphologies of samples in different states: (a) T6, (b) RRA, (c) H3C6A6, (d) H3C6A12, (e) H3C6A18, (f) H3C6A24. 

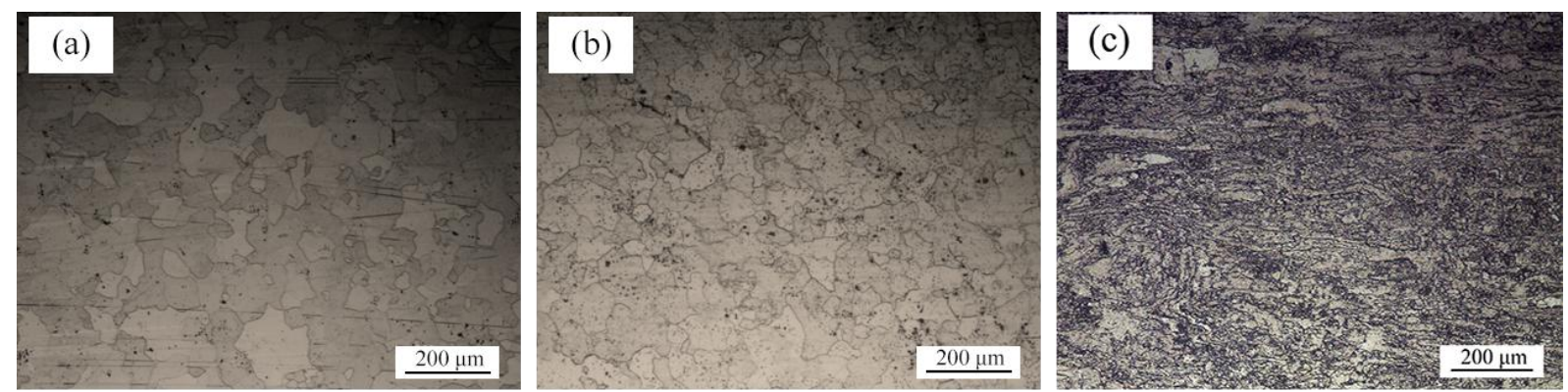

Fig. 3. Optical micrographs of Al-Zn-Mg-Cu alloys in different states: (a) T6, (b) RRA, (c) $30 \% \mathrm{SSHR}+60 \% \mathrm{CR}$.

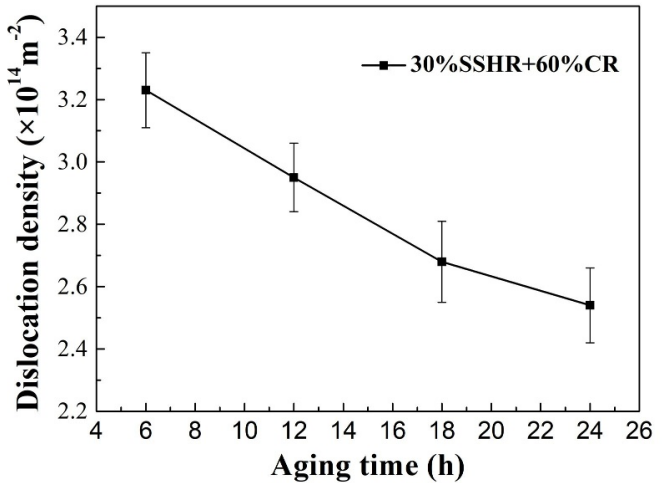

Fig. 4. Dislocation density of NTMT processed Al-Zn-Mg-Cu alloys.

Fig. 5 shows the orientation distribution functions (ODF) of aluminum alloys in T6 and NTMT states. Fig. 5(a) shows the texture components in the T6 sample consist mainly of the recrystallization textures of Cube $\{001\}<100>$ and strong deformation texture $\mathrm{S}$ $\{123\}<634>$. Compared with the T6 sample, the rolling textures increase remarkably while the recrystallization textures of Cube $\{001\}<100>$ and R-Cube $\{001\}<110>$ decrease. This is attributed to the strong rearrangement of grain orientations that occurred during rolling deformation. So the texture components in the NTMT processed aluminum alloys are mainly deformation textures, such as Copper $\{112\}<111>$ and $\mathrm{S}\{123\}<634>$ as shown in Fig. 5(b). In addition, it is worth noting that the texture $\mathrm{P}\{011\}<111>$ can be observed in aluminum alloy after the $30 \% \mathrm{SSHR}+60 \% \mathrm{CR}$ process.

\subsection{TEM observation}

The transmission electron micrographs of Al-Zn-Mg-Cu alloys in different states are presented in Figs. 6 and 7. From Fig. 6(a, b), it can be found that the sizes and the distribution of intragranular precipitates in T6 and RRA samples are similar, and the fine $\eta^{\prime}$ phases are uniformly
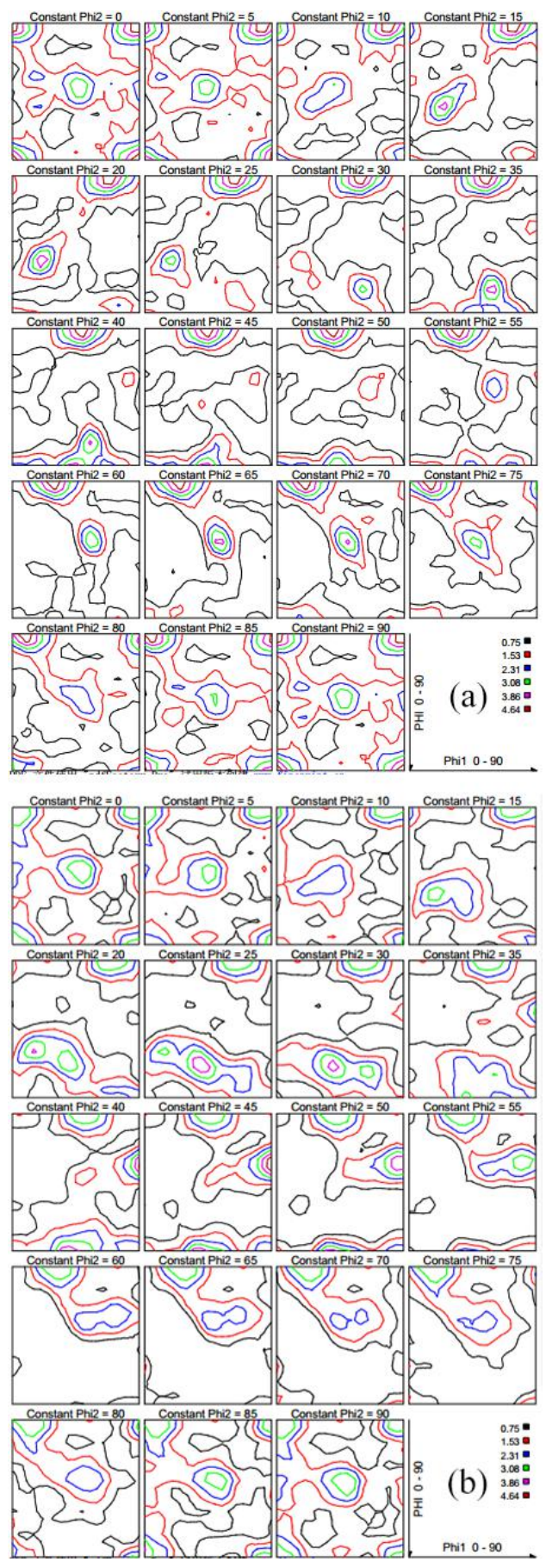

Fig. 5. ODF charts of aluminum alloys in different states: (a) T6, (b) $30 \% \mathrm{SSHR}+60 \% \mathrm{CR}$. 
distributed in the matrix. The grain boundary precipitates (GBPs) in the T6 and RRA tempers are larger than intragranular precipitates. However, the GBPs in the T6 are continuous, while those in the RRA are discontinuous. In addition, obvious precipitation-free zones (PFZ) can be found by observing the GBPs in the T6 and RRA.
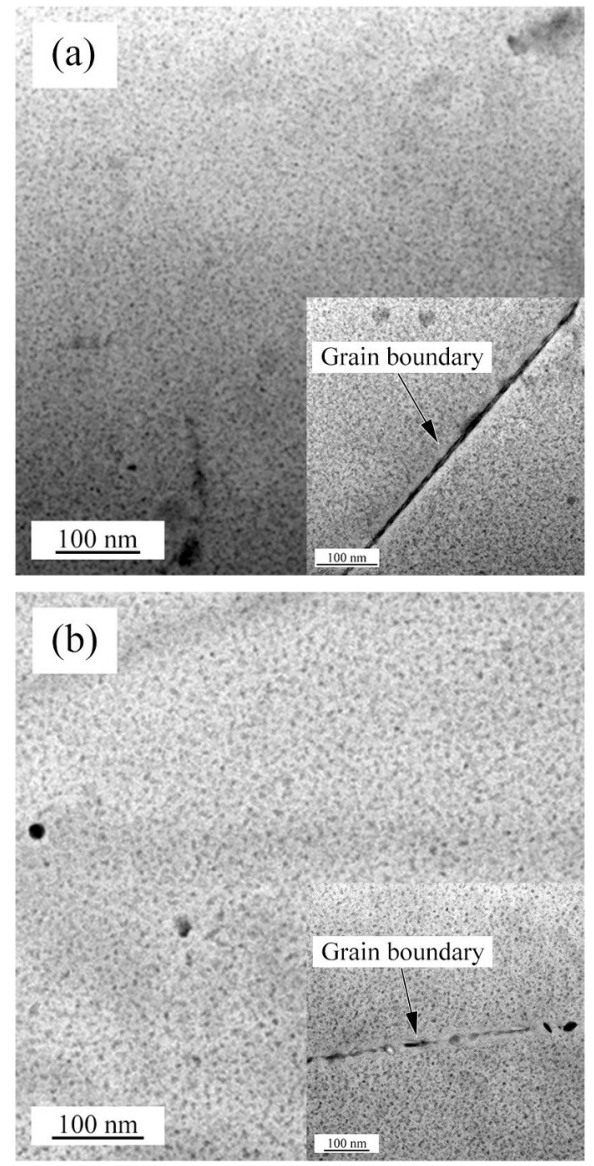

Fig. 6. Transmission electron micrographs of (a) T6 and (b) RRA processed Al-Zn-Mg-Cu alloys.

Due to a large amount of deformation in the NTMT, there are many dislocations in alloys. Since the ageing temperature is insufficient to eliminate dislocations formed during deformation, thus many dislocations are preserved and tangled with each other. And the nano-sized $\eta^{\prime}$ phase gradually grows (Fig. 7), and the dislocation density gradually decreases as the ageing time increases. According to the diffraction pattern in Fig. $7(\mathrm{c}, \mathrm{d})$, it can be concluded that there is a GP zone in the ageing time of 6 to 18 hours, but there is no obvious GP zone diffraction spot after ageing for 24 hours, which indicates the transition of the GP zone to the $\eta^{\prime}$ phase. The precipitation sequence was GP zone $\rightarrow \eta^{\prime} \rightarrow \eta[17]$.
Fig. 8 represents the TEM images of grain boundary in NTMT processed samples. The GBPs in NTMT processed samples change from continuous distribution to discontinuous distribution. The GBPs of H3C6A6 and H3C6A12 samples are continuously distributed, while the GBPs of samples processed by H3C6A18 and H3C6A24 are coarse and discontinuously distributed.

\section{Discussions}

\subsection{Effect of NTMT on tensile properties in $\mathrm{Al}-\mathrm{Zn}-\mathrm{Mg}-\mathrm{Cu}$ alloy}

$\mathrm{Al}-\mathrm{Zn}-\mathrm{Mg}-\mathrm{Cu}$ alloy is a typical ageing hardening alloy, and nanoprecipitates formed during ageing treatment are the main factor determining the strength of aluminum alloys. Plastic deformation can introduce dislocation lines in aluminum alloys [18], and the dislocations introduced by deformation in the NTMT also have an impact on the tensile properties of aluminum alloys. Thus, the tensile properties of samples obtained by different treatment processes are quite different. For ageing hardening aluminum alloys, the yield strength can be described by the following Equation (4) [19]:

$$
\sigma_{y}=\Delta \sigma_{g b}+M\left[\tau_{0}+\Delta \tau_{c}+\left(\Delta \tau_{d}^{2}+\Delta \tau_{p}^{2}\right)^{1 / 2}\right]
$$

where $\sigma_{y}$ is the yield strength of aluminum alloys, $\Delta \sigma_{g b}$ is the strength change caused by grain boundary strengthening, $M$ is an orientation factor (often termed the Taylor factor), $\tau_{0}$ is the friction stress of $\sim 7 \mathrm{MPa}, \Delta \tau_{c}$ is the strength change caused by solution strengthening, $\Delta \tau_{d}$ is the strength change caused by dislocation, and $\Delta \tau_{p}$ is the strength change caused by precipitates.

All samples have been processed by overageing and can be regarded as their solid solution atoms precipitated, so the effect of solution strengthening on the strength of aluminum alloys can be ignored. The sizes of the precipitates of T6 and RRA samples are similar, and they are uniformly distributed on the aluminum matrix (Fig. 6). In addition, the dislocations in T6 and RRA samples are considered to be substantially eliminated during solid solution. Therefore, the effect of dislocations on strength can be ignored for the alloys in the T6 and RRA. Therefore, the strength of the T6 and RRA samples is similar due to the similar grain sizes. 

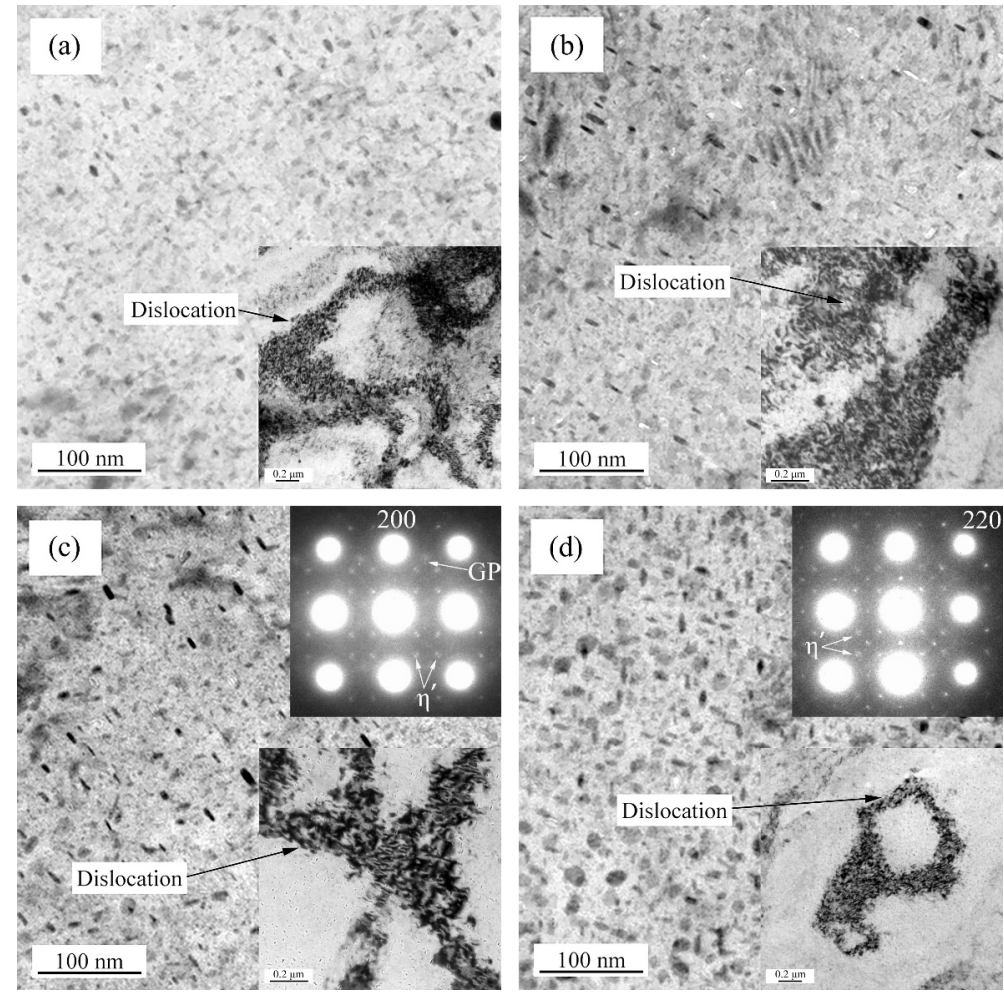

Fig. 7. Transmission electron micrographs of NTMT processed Al-Zn-Mg-Cu alloys: (a) H3C6A6, (b) H3C6A12, (c) H3C6A18, (d) H3C6A24.
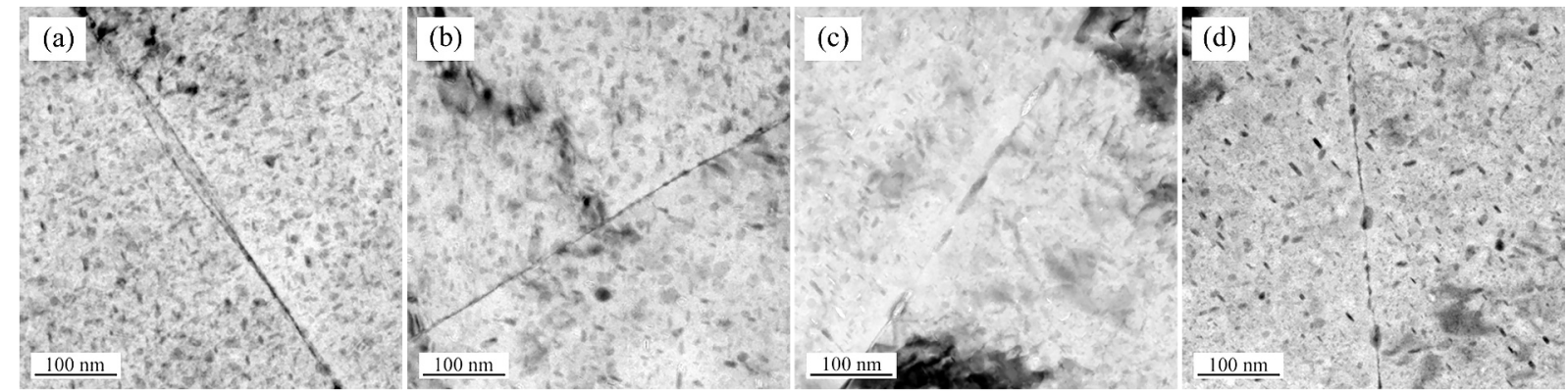

Fig. 8. Transmission electron micrographs of grain boundary in NTMT processed samples: (a) H3C6A6, (b) H3C6A12, (c) H3C6A18, (d) H3C6A24.

With the introduction of dislocations in the NTMT, the contribution due to dislocations $\left(\Delta \tau_{d}\right)$ can be described by the following Equation (5) [20],

$$
\Delta \tau_{d}=\alpha G b \rho^{1 / 2}
$$

where $\rho$ is the dislocation density, $\alpha, G$ and $b$ are constants. Therefore, the greater the dislocation density, the greater its contribution to strength. With the extension of ageing time, the dislocation density of NTMT processed samples gradually decreases (Fig. 4), and the nanoprecipitate grows, resulting in the decrease of strength. In addition, the dislocations create links between nanoprecipitates, improving the efficiency of the transformation of GBPs from small nanoprecipitates to large ones, which can lead to the increase of the size of precipitates after NTMT compared to the T6 and RRA (Fig. 6 and Fig. 7). Thus, the strength of NTMT processed aluminum alloys is obviously higher than that of T6 and RRA because of the ageing precipitation strengthening and dislocations strengthening.

The Taylor factor value of typical deformation textures (Copper, S, Brass) is obviously higher than that of recrystallization Cube textures, and the Taylor factor value of $\mathrm{P}$ texture is the highest. $\mathrm{P}$ texture only appears in the aluminum alloy under the process conditions of $30 \%$ SSHR $+60 \%$ CR (Fig. 5). Combined with Fig. 5 and 
Table 4, it can be concluded that the average Taylor factor of samples after $30 \% \mathrm{SSHR}+60 \% \mathrm{CR}$ process is much higher than that of T6, which can also explain the improvement of the strength of NTMT processed aluminum alloys.

The ductility of samples is related to dislocations during the tensile test. After the NTMT, the dislocations are introduced into the aluminum alloys due to deformation, but as the ageing time increases, the dislocation tangles gradually decrease, which provides more space for the accumulation of dislocations in the tensile test, so the elongation of samples is improved (Table 2). The elongation of H3C6A6 was 9.7\%. The elongation of $\mathrm{H} 3 \mathrm{C} 6 \mathrm{~A} 12$ and $\mathrm{H} 3 \mathrm{C} 6 \mathrm{~A} 18$ increased to $10.1 \%$ and $10.6 \%$, respectively. However, the elongation of the sample H3C6A24 decreased to $9.4 \%$ due to the growth of the precipitates, which was not conducive to the ductility of the aluminum alloy.

Table 4. Taylor factor of typical texture.

\begin{tabular}{cc}
\hline Textrue & Talor factor $(\mathrm{M})$ \\
\hline Copper $\{112\}<111>$ & 3.70 \\
$\mathrm{~S}\{123\}<634>$ & 3.33 \\
Brass $\{011\}<211>$ & 3.17 \\
Cube $\{001\}<100>$ & 2.45 \\
$\mathrm{P}\{011\}<111>$ & 3.97 \\
\hline
\end{tabular}

\subsection{Effect of NTMT on electrical conductivity in Al-Zn-Mg-Cu alloy}

The electrical conductivity of NTMT processed samples is between T6 and RRA, and the electrical conductivity of NTMT processed samples increases gradually with the extension of ageing time (Table 3). According to Mathiessen rule [21], the electrical conductivity is described by the following Equation (6):

$$
\rho=\rho_{0}-\Delta \rho_{s}+\Delta \rho_{p}-\Delta \rho_{v}-\Delta \rho_{d}-\Delta \rho_{g}
$$

where $\rho_{0}$ is the conductivity of pure aluminum, $\Delta \rho_{s}$ is the effect of solid solution of alloy elements on conductivity, $\Delta \rho_{p}$ is the effect of precipitates on conductivity, $\Delta \rho_{v}$ is the effect of the vacancy on conductivity, $\Delta \rho_{d}$ is the effect of dislocation on conductivity, and $\Delta \rho_{g}$ is the effect of grain boundary on conductivity. Defects such as vacancies and dislocations lead to the decrease of electrical conductivity of aluminum alloys. Precipitates of alloys have two effects on its electrical conductivity. On the one hand, the lattice distortion of the aluminum matrix is reduced due to the precipitation of solute atoms, which is conducive to the improvement of conductivity. On the other hand, the nanoprecipitates can hinder the movement of electrons and scatter electrons, which is not conducive to electrical conductivity.

The electrical conductivity of RRA processed samples is the highest among all samples (Table 3). The aluminum alloy in the RRA is overageing, so the solute atoms precipitate more completely than T6. It is more helpful to reduce the adverse effect of lattice distortion on electrical conductivity, and the formation of coarse and discontinuous GBPs is also beneficial to the electrical conductivity. Also, NTMT treatment introduces dislocations into the samples. For one thing, it promotes the formation of precipitates in aluminum alloys and improves its electrical conductivity. For another, it can strengthen the lattice distortion and have an adverse effect on the electrical conductivity. By comparing the electrical conductivity of samples with different treatments, it can be found that the promotion of dislocations on the precipitation of aluminum alloys has a greater effect on the conductivity. Therefore, the electrical conductivity of NTMT processed aluminum alloys is higher than that of T6. With the ageing time prolonging, precipitates of aluminum alloys are more sufficient, the density of dislocations gradually decreases due to the recovery, so the conductivity gradually increases. The electrical conductivity of aluminum alloys can reflect the resistance to intergranular corrosion to a certain extent, and there is a positive correlation between corrosion property and electrical conductivity. The electrical conductivity of NTMT processed alloys is significantly increased compared to $\mathrm{T} 6$, which indicates that the intergranular corrosion resistance is improved.

\subsection{Effect of NTMT on corrosion property in $\mathrm{Al}-\mathrm{Zn}-\mathrm{Mg}-\mathrm{Cu}$ alloy}

The intergranular corrosion resistance of aluminum alloys is mainly affected by the GBPs [22, 23]. The intergranular corrosion of aluminum alloys is mainly electrochemical corrosion [24]. The potential difference between the aluminum matrix and the grain boundary makes the grain boundary more susceptible to corrosion. 
The corrosion potential of $\eta$ phases along grain boundaries is more negative than that of PFZ and matrix, causing GBPs to undergo anodic dissolution. The anodic dissolution rate of aluminum alloys mainly depends on the dissolution rate of GBPs.

After pre-ageing at $120^{\circ} \mathrm{C} / 24 \mathrm{~h}$, the aluminum alloy in the RRA formed fine and uniformly distributed precipitates in the crystals. When the temperature rose to $195^{\circ} \mathrm{C}$, the precipitates inside the grain would re-dissolve into the aluminum matrix and GBPs would continue to grow and the intermittent distribution would form. Finally, finely dispersed precipitates re-formed inside the grain after $120^{\circ} \mathrm{C} / 24 \mathrm{~h}$, and coarse and intermittently distributed precipitates at the grain boundaries were retained (Fig. 6(b)). The GBPs in the T6 are continuously distributed, which tend to be an anodic corrosion channel in the corrosive medium, accelerating corrosion cracking. Therefore, the intergranular corrosion depth of the aluminum alloy in the RRA is much smaller than that of T6.

Meanwhile, the dislocations introduced by NTMT can create links between nanoprecipitates, improving the transformation efficiency of GBPs from small precipitates to large ones. The GBP of NTMT processed aluminum alloy is mainly the $\eta$ phase. The coarser and more spaced GBPs can capture the surrounding hydrogen atoms and provide a position for them to form hydrogen molecules to escape, thus reducing the concentration of hydrogen atoms on the grain boundaries [25]. Then hydrogen embrittlement will be avoided and the rate of crack growth will be reduced, thereby improving the intergranular corrosion resistance [26]. In addition, the coarse GBPs can also reduce the corrosion current density, which can improve the corrosion sensitivity of aluminum alloys. As shown in Fig. 8(a,b), the GBPs in H3C6A6 and H3C6A12 (under ageing) are continuously distributed, which lead to a high corrosion sensitivity. However, the H3C6A18 and H3C6A24 (peak ageing) states samples show some discontinuity in the arrangement of precipitates along the grain boundary, which can block anodic dissolution channels and have better corrosion resistance [22]. Therefore, it can be concluded that the intergranular corrosion resistance gradually improves with the extension of ageing time.

Besides, the fibrous grain structure formed in deformation hinders the stress corrosion crack growth.

According to references $[25,27,28]$, the $\mathrm{Cu}$ content of the GBPs is an important factor affecting the corrosion resistance of $\mathrm{Al}-\mathrm{Zn}-\mathrm{Mg}-\mathrm{Cu}$ alloys, followed by the morphology of matrix precipitate (MPT), and other factors such as the segregation of solute atoms at grain boundaries, the width of PFZ, and the number of solid atoms.

\section{Conclusions}

1) The NTMT can significantly improve the strength of $\mathrm{Al}-\mathrm{Zn}-\mathrm{Mg}-\mathrm{Cu}$ alloys while maintaining good ductility. On the treatment of $30 \%$ continuous Solid solution-Hot rolling (SSHR) $+60 \%$ cold rolling (CR) +ageing $\left(120^{\circ} \mathrm{C} / 6 \mathrm{~h}\right)$, the highest yield strength and ultimate tensile strength reached $643 \mathrm{MPa}$ and 664 $\mathrm{MPa}$ respectively, meanwhile, the elongation can be maintained at $9.7 \%$.

2) The NTMT enables Al-Zn-Mg-Cu alloys to improve electrochemical corrosion resistance and intergranular corrosion resistance. Under $30 \% \mathrm{SSHR}+60 \% \mathrm{CR}$, the electrochemical corrosion current density of aluminum alloys after ageing at $120^{\circ} \mathrm{C}$ for 18 hours is lower than that of RRA, and the intergranular corrosion depth of NTMT after ageing for 12 hours is lower than that of RRA.

3) The mechanism of the excellent combination of strength and ductility is thought to be the synergistic effect of dislocations substructures, texture configuration, and nanoprecipitates. The recrystallization texture $\mathrm{P}\{011\}<111>$ present in NTMT processed aluminum alloys is an important factor affecting the strength of the alloys.

4) The improvement of intergranular corrosion resistance results from changes in the dislocations and micro-morphology of GBPs. The introduction of dislocations into NTMT processed alloys creates links between precipitates and improves the transformation efficiency of GBPs from small precipitates to large ones. The formation of coarse and discontinuous GBPs after ageing can block anodic dissolution channels along grain boundaries to reduce the rate of anodic dissolution and avoid hydrogen embrittlement, thereby improving the corrosion resistance. 
The authors gratefully acknowledge the financial support from the National Natural Science Foundation of China (Grant No. 51011120052 and 50871123) and the double first-class discipline construction program of Hunan Province.

\section{References:}

[1] T. Tang, G.W. Zhou, Z.H. Li, D.Y. Li, L.M. Peng, Y.H. Peng, P.D. Wu, H.M. Wang and M. Lee, Int. J. Plast. 116, 159-191 (2019).

[2] M. Tisza and I. Czinege, Int. J. Light Mater. Manuf. 1, 229-238 (2018).

[3] A. Heinz, A. Haszler, C. Keidel, S. Moldenhauer, R. Benedictus and W. S. Miller, Mater. Sci. Eng. A 280, 102-107 (2000).

[4] W.S. Miller, L. Zhuang, J. Bottema, A.J. Wittebrood, P. De Smet, A. Haszler and A. Vieregge, Mater. Sci. Eng. A 280, 37-49 (2000).

[5] X.Y. Peng, Q. Guo, X.P. Liang, Y. Deng, Y. Gu, G.F. Xu and Z.M. Yin, Mater. Sci. Eng. A 688, 146-154 (2017).

[6] L.L. Wei, Q.L. Pan, L. Feng, Y.L. Wang and H.F. Huang, Mater. Corros. 66, 54-60 (2015).

[7] R. Woodward, Mater. Des. 10, 248-254 (1989).

[8] B.M. Cina, Reducing the Susceptibility of Alloys, Particularly Aluminium Alloys, to Stress Corrosion Cracking, US Patents (1974).

[9] E.D. Russo, M. Conserva, F. Gatto and H. Markus, Met. Trans. 4, 1133-1144 (1973).

[10] W.T. Huo, L.G. Hou, H. Cui, L.Z. Zhuang and J.S. Zhang, Mater. Sci. Eng. A 618, 244-253 (2014).

[11] H. Li, W. Xu, Z.X. Wang, B.J. Fang, R.G. Song and Z.Q. Zheng, Mater. Sci. Eng. A 650, 254-263 (2016).

[12] J. Zuo, L. Hou, J. Shi, H. Cui, L. Zhuang and J. Zhang, Mater. Charact. 130, 123-134 (2017).

[13] Z.G. Chen, J.K. Ren, J.S. Zhang, J.Q. Chen, H. Y. Jin and L. Fang, Rare Metal Mat. Eng. 44, 2341-2346 (2015).

[14] J.K. Ren, Z.G. Chen, J. Peng, W.J. Ma and S.P. Ringer, J. Alloy. Compd. 764, 679-683 (2018).

[15] Y.H. Zhao, X.Z. Liao, Z. Jin, R.Z. Valiev and Y.T. Zhu, Acta Mater. 52, 4589-4599 (2004).

[16] T. Ungár, S. Ott, P.G. Sanders, A. Borbély and J.R. Weertman, Acta Mater. 46, 3693-3699 (1998).

[17] C.H.J. Davies, N. Raghunathan and T. Sheppard,
Acta Metall. Mater. 42, 309-318 (1994).

[18] Z.G. Chen, J.Q. Chen, X.B. Guo, J.K. Ren and Y.L. Deng, Mater. Sci. Eng. A 669, 33-40 (2016).

[19] M.J. Starink and S.C. Wang, Acta Mater. 51, 5131-5150 (2003).

[20] P. Luo, D.T. McDonald, W. Xu, S. Palanisamy, M. S. Dargusch and K. Xia, Scr. Mater. 66, 785-788 (2012).

[21] J.S. Dugdale and Z.S. Basinski, Phys. Rev. 157, 552-560 (1967).

[22] L.L. Wei, Q.L. Pan, L. Feng, Y.L. Wang and H. F. Huang, Mater. Corros. 66, 54-60 (2015).

[23] X.Y. Peng, Q. Guo, X.P. Liang, Y. Deng, Y. Gu, G.F. Xu and Z.M. Yin, Mater. Sci. Eng. A 688, 146-154 (2017).

[24] Y. Luo, X.J. Xu, G.C. Wu, Y.K. Zhang, T. Song, B. Wang, F.B Zhang, C. Cheng and Z.D. Fei, Rare Metal Mat. Eng. 41, 262-265 (2012).

[25] D.A. Hardwick, A.W. Thompson and I.M. Bernstein, Metall. Trans. A 14, 2517-2526 (1983).

[26] D. Nguyen, A.W. Thompson and I.M. Bernstein, Acta Metall. 35, 2417-2425 (1987).

[27] S.P. Knight, N. Birbilis, B.C. Muddle, A.R. Trueman and S.P. Lynch, Corrosion Sci. 52, 4073-4080 (2010).

[28] J.K. Park and A.J. Ardell, Acta Metall. Mater. 39, 591-598 (1991). 